\title{
PLANEJANDO CORREDORES ECOLÓGICOS PARA A INTEGRAÇÃO DA REGIÃO METROPOLITANA DA GRANDE SÃO LUÍS
}

\author{
José Antonio Viana Lopes, Yata Anderson Gonzaga Masullo \& Paulo Henrique Correia Silva. \\ Secretaria de Estado das Cidades e Desenvolvimento Urbano - SECID. \\ Coordenador da Pesquisa: José Antonio Viana Lopes. \\ joseantonioarq@gmail.com
}

\section{RESUMO}

O presente estudo analisa a viabilidade de corredores ecológicos na Grande São Luís a partir do avanço da expansão urbana sobre as Unidades de Conservação, e até mesmo no seu interior, e com a deficiência de políticas públicas, o que acarreta uma série de danos, como alterações na dinâmica da paisagem e fragmentação dessas áreas protegidas. Nesse contexto, a pesquisa utiliza técnicas ligadas ao Sistema de Informações Geográficas - SIG para demonstrar a viabilidade e a necessidade de implantação do corredor ecológico da APA do Itapiracó - Upaon-Açu/Miritiba/Alto Preguiças, nos moldes de um parque urbano linear, como forma de integrar as Unidades de Conservação - UC. Por fim, é necessário salientar a importância deste estudo, assim como o seu potencial inovador, por incluir na proposta de corredores, UC's que se encontram em uma região sob forte pressão urbana.

Palavras-Chave: Grande São Luís, Unidades de Conservação, Corredores Ecológicos.

\begin{abstract}
The present study analyzes the viability of ecological corridors in the Greater São Luis from the advance of the urban expansion in its limits, and even in its interior; and the lack of public policies. This entails a series of damages, such as changes in its landscape dynamics and the fragmentation of protected areas. In this context, the research uses techniques linked to the Geographic Information System - GIS. Therefore, the research demonstrates the viability and the need to implement the ecological corridor of the protect area Itapiracó - Upaon - Açu / Miritiba / Alto Preguiças, in the form of a linear urban park, as a way of integrating the Conservation Units - UC. Finally, it is necessary to emphasize the importance of this study, as well as its innovative potential, to include in the proposal of corridors, UC's that are in a region under strong urban pressure.
\end{abstract}

Key words: Greater São Luis, Conservation Units, Ecological Corridors. 


\section{INTRODUÇÃO}

A Região Metropolitana da Grande São Luís (RMGSL), composta por treze municípios, constitui um território complexo caracterizado pela diversidade em questões sociais, econômicas e ambientais. A delimitação da Grande São Luís fundamenta-se não apenas por critérios de homogeneidade, mas por complementaridade e coesão territorial, bem como pela necessidade de integração econômica e diminuição das desigualdades sociais.

Esta pesquisa está baseada na hipótese de que os recursos e instrumentos de preservação ambiental, em particular a criação de corredores ecológicos, podem se constituir em um dos principais fatores de integração socioespacial da Região Metropolitana da Grande São Luís.

A criação de espaços públicos visando à proteção dos recursos naturais de forma integrada é cada vez mais necessária diante do atual cenário em que vivemos, caracterizado principalmente pela rápida expansão urbana e por um modelo de crescimento econômico onde a exploração dos recursos ambientais, acarreta em graves impactos ambientais (Pedlowski et al., 1999). Área de Preservação Permanente, Reserva Legal, Terras Indígenas e Quilombolas, Áreas de Reconhecimento Internacional e Unidades de Conservação (UC's), são algumas das tipologias de áreas protegidas.

Dentre as tipologias de áreas protegidas mais conhecidas, destacam-se as Unidades de Conservação (UC’s), definidas pelo Sistema Nacional de Unidades de Conservação (SNUC - Lei no 9.985/2000) em seu Art. $2^{\circ}$, inciso I, como espaços territoriais legalmente instituídos pelo poder público, objetivando a conservação de seus recursos ambientais, sob regime especial de administração (Brasil, 2000).

Visando à conservação e/ou preservação de seus recursos naturais, o Estado do Maranhão possui atualmente 23 UC's, compreendendo as de Uso Sustentável e Proteção Integral (Masullo, 2015). Entre estas Unidades de Conservação da RMGSL, estão o Parque Estadual do Sítio Rangedor, o Parque Estadual do Bacanga e as Áreas de Proteção Ambiental (APA) do Itapiracó, Maracanã, UpaonAçu/Miritiba/Alto Preguiças, Baixada Maranhense, Reentrâncias Maranhenses, além do Parque das Dunas, em processo de criação.

No entanto, Costa et al. (2008), advertem que uma vez localizadas em áreas urbanizadas, as UC's estão expostas a impactos cada vez mais acentuados, oriundos das atividades humanas, como a deposição de resíduos sólidos e a supressão vegetal. Tal realidade reflete a ineficiência do planejamento e gestão destes espaços, que em sua maioria apresentam fiscalização deficiente, ausência de regulamentação fundiária, inexistência ou desatualização de planos de manejo, além da falta de recursos financeiros e de recursos humanos.

No intuito de conservar e contornar o atual cenário de deficiência em termos de gestão e planejamento nestes espaços, o surgimento de práticas e metodologias, como a educação ambiental e os corredores ecológicos, se fazem necessárias e importantes (Valenti et al., 2012; Aranha, Almirante, 2007).

De acordo com Seoane et al. (2010), os corredores ecológicos destacam-se como partes de estratégias para a conservação de ambientes fragmentados, desde a década de 1970, no entanto, esta importante metodologia surgiu na legislação brasileira apenas em 2000, pelo SNUC (Lei no 9.985), sendo definido em seu Art. $2^{\circ}$, inciso XIX, como porções de ecossistemas naturais ou seminaturais, objetivando a ligação de unidades de conservação, e consequentemente possibilitando um maior fluxo de genes e o movimento da biota, assim como a recolonização de áreas degradadas.

O presente estudo desenvolve-se a partir da análise da paisagem a qual indicou a viabilidade de corredores ecológicos na RMGSL utilizando técnicas relacionadas a Sistemas de Informações Geográficas (SIG's) que mapearam a dinâmica espaço temporal do uso e ocupação do solo das UC's (Masullo, 2015). Deste modo, a pesquisa possibilita a avaliação e o monitoramento das dinâmicas e tendências no processo de uso e ocupação do solo na região, buscando interação entre as Unidades de Conservação e a consequente preservação destas áreas e a requalificação do seu entorno pela criação de novos espaços públicos.

\section{MÉTODO, TÉCNICAS E PROCEDIMENTOS METODOLÓGICOS}

Para atingir o objetivo de desenvolver corredores ecológicos interligando as Unidades de Conservação da Região Metropolitana da Grande São Luís, adotando o conceito de corredor verde urbano que pressupõe o uso e ocupação equilibrados das áreas de proteção ambiental, a pesquisa se propôs a: 
- Analisar as condições socioambientais que incidem sobre a vulnerabilidade das unidades de conservação da RMGSL;

- Mapear a dinâmica espaço-temporal no processo de uso e ocupação do solo destas áreas;

- Analisar a viabilidade para implantação de corredores ecológicos na Grande São Luís;

- Definir diretrizes de projeto para intervenções urbanas, visando a implantação de corredores verdes urbanos com funções de corredor ecológico.

Para esta pesquisa, idealizou-se um modelo baseado em técnicas de SIG's (Sistema de Informações Georeferenciadas). Em linhas gerais, o estudo evidencia a integração de uma série de dados específicos de forma multidisciplinar, tratando da correlação dos elementos envolvidos. Esta pesquisa está organizada em três etapas complementares.

Na Etapa 1, emprega-se o método de Análise Multicritério com o objetivo de correlacionar os indicadores socioambientais que influenciam e caracterizam a dinâmica da paisagem e a qualidade de vida das UC's, agregando um valor significativo na tomada de decisão, na medida em que permitem análises a partir de indicadores e índices sintéticos. A aplicação destes procedimentos resultou na indicação das possibilidades de implantação de corredores ecológicos entre as Unidades de Conservação da llha do Maranhão.

$\mathrm{Na}$ Etapa 2, a equipe analisa e avalia as três possibilidades indicadas pela pesquisa: a) Corredor APA do Itapiracó / APA Upaon-Açu - Miritiba - Alto do Rio Preguiças; b) Corredor Parque Estadual do Bacanga / APA do Maracanã / APA Upaon-Açu - Miritiba - Alto do Rio Preguiças; e c) Corredor Estação Ecológica do Rangedor; Parque das Dunas; Sitio Santa Eulália / lagoa da Jansen, considerando aspectos como a interação dos elementos que compõem a unidade da paisagem, para a definição da localização, perímetro e área de influência da intervenção urbana a ser implantada como projeto piloto de Corredor Verde entre Unidades de Conservação na Região Metropolitana da Grande São Luís.

O objetivo é a criação de novas estratégias de implementação de políticas públicas integradas com a realidade e principalmente, alinhadas ao contexto local e às funções públicas de interesse comum listadas pela Lei Complementar $n^{\circ} 174$ de 25 de maio de 2015. Sob essa perspectiva, o estudo se desenvolve a partir de técnicas e procedimentos metodológicos baseados em Gascon; Tabarelli (2005), Louzada et al. (2010), Araújo et al. (2014), para o desenvolvimento de propostas viáveis de corredores ecológicos para a Região Metropolitana.

A Etapa 3 constitui o desenvolvimento do projeto de intervenção urbana para criação de um corredor ecológico nos moldes de um Corredor Verde Urbano, a partir das diretrizes e estratégias identificadas ou definidas pela pesquisa. Esta Etapa 3 está em desenvolvimento e tem como objeto o Corredor APA do Itapiracó / APA Upaon-Açu - Miritiba - Alto do Rio Preguiças ${ }^{1}$.

\subsection{Técnicas para Identificação de Corredores Ecológicos na Grande São Luís.}

Dentre os métodos multicritérios optou-se pelo reconhecido Analytical Hierarchy Process (AHP) ou Processo Hierárquico Analítico que consiste em um método multicritérios de modelagem de dados, que permite a ponderação de diversos fatores envolvidos em processos de diagnósticos e tomadas de decisão, auxiliando a integração objetiva de indicadores (Oliveira, 2008). O método desenvolvido por Saaty em 1977 é uma técnica que possui a finalidade de atenuar a subjetividade das interpretações, por meio do estabelecimento de uma hierarquia de soluções com a quantificação dos atributos e suas correlações (Dias, 2014).

Corroborando com a construção conceitual, Saito (2015); Coutinho (2015); Argyriou et al. (2016) visualizam o método AHP como uma estrutura hierárquica de decisão, composta por níveis de importância das relações inerentes ao processo, onde existe a categorização e ponderação de matrizes de comparação para cada nível.

Conforme Silva Júnior (2015), a obtenção do modelo hierárquico depende da construção de matrizes quadradas recíprocas positivas, cuja ordem será igual ao número de alternativas. Posteriormente, para cada critério ou subcritério faz-se o mesmo progressivamente, para definir o grau de importância de cada uma das variáveis, contribuindo com a funcionalidade e coerência nos níveis de correlação (Quadro 01).

\footnotetext{
${ }^{1}$ Denominado, para fins do projeto, de Corredor Itapiracó/Upaon-Açu.
} 


\begin{tabular}{|c|c|}
\hline VALORES & IMPORTÂNCIA MÚTUA \\
\hline $1 / 9$ & Extremamente menos importante que \\
\hline $1 / 7$ & Muito fortemente importante que \\
\hline $1 / 5$ & Fortemente menos importante que \\
\hline $1 / 3$ & Moderadamente menos importante que \\
\hline 1 & Igualmente importante a \\
\hline 3 & Moderadamente mais importante que \\
\hline 5 & Fortemente mais importante que \\
\hline 7 & Muito fortemente mais importante que \\
\hline 9 & Extremamente mais importante que \\
\hline $\begin{array}{c}\text { Quadro 01: Escala de Comparadores. } \\
\text { (Louzada et al., 2010). }\end{array}$
\end{tabular}

Esse procedimento baseia-se em três princípios: decomposição, julgamentos comparativos e síntese de prioridades, onde sua estrutura hierárquica delimita-se em Nível I (Objetivo a ser alcançado), Nível II (critérios) e Nível III (alternativas). Dessa forma, define-se o peso de cada uma das variáveis e/ou indicadores com sua soma igual a 1, como uma condição necessária para a combinação linear ponderada dos critérios (Conde, 2013; Dias, 2014).

De acordo com Raffo (2012); Gauer (2015), essa estrutura possibilita que a partir de variáveis sociais, econômicas e ambientais, se estabeleça cenários para tomada de decisão. Em suma, o método AHP pondera quantitativamente variáveis mediante correlações qualitativas, organizando e estabelecendo um modelo racional de combinação de dados (Sahoo et al., 2016).

A: Coleta de Dados UC e RMGSL: A pesquisa documental se desenvolveu por meio da consulta na Secretaria de Estado das Cidades e Desenvolvimento Urbano - SECID, Secretaria de Meio Ambiente Estadual - SEMA e no Ministério do Meio Ambiente.

Além dos dados institucionais foi estruturada a análise bibliográfica a partir de estudos nacionais e internacionais, por meio do portal de periódicos da CAPES (Coordenação de Aperfeiçoamento de Pessoal de Nível Superior), SCIELO e Google Acadêmico, a partir das palavras chaves: Corredores Ecológicos, Vulnerabilidade Socioambiental - Indicadores Socioambientais - Áreas Protegidas - Unidades de Conservação - Análise Multicritério.

A coleta de dados in loco realizou-se com a finalidade de validar as informações levantadas na pesquisa cartográfica, dirimir dúvidas da fotointerpretação e fazer registros fotográficos.

B: Corredores Ecológicos: Para desenvolvimento do estudo, foi necessária a adaptação das metodologias de Gascon; Tabarelli (2005); Louzada et al. (2010); Marques, et al. (2011); Araújo et al. (2014), onde utilizase o SIG para analisar variáveis ambientais múltiplas, como forma de propor um modelo para desenho de interligação das UC's da Ilha do Maranhão por meio de corredores ecológicos.

Essa análise consiste na sobreposição de mapas temáticos, elaborados a partir da delimitação do uso e ocupação da terra (variáveis ambientais), que são considerados como unidades de paisagem. Para cada variável ambiental, atribui-se um peso, o qual posteriormente serviu de base de cálculo, por intermédio de um algoritmo específico, gerando variáveis ambientais a serem utilizadas na confecção de mapas temáticos: a) Área de Preservação Permanente (APP); b) uso da terra e c) declividade, conforme demonstrado no esquema gráfico da Figura 01, abaixo. 

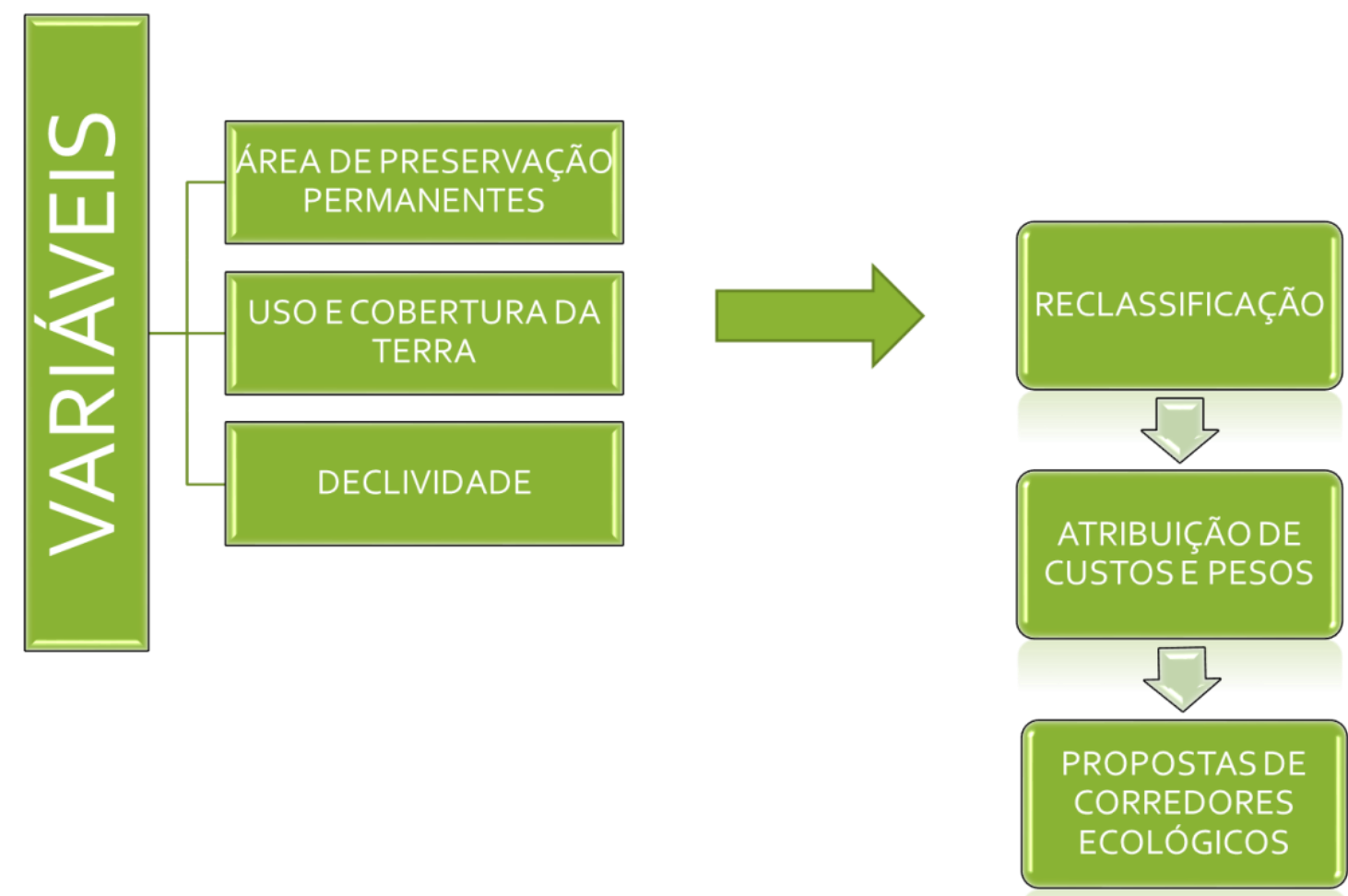

Figura 01: Fluxograma dos procedimentos técnicos. (Lousada et al., 2010).

Estes dados foram extraídos a partir do processamento digital das imagens aéreas com resolução espacial de $0,5 \mathrm{~m}$ do ano de 2011 cedidas pela Prefeitura de São Luís para sanar dúvidas da fotointerpretação, com o uso do software de geoprocessamento. Referente à declividade foram utilizadas imagens SRTM de 30 metros de resolução espacial obtidas no site da Earth Explorer.

No caso específico foram selecionadas para as UC's, com posterior processamento e análise por meio de métodos e técnicas integradas ao ambiente SIG.Para o processamento e classificação supervisionada empregou-se um sistema de amostragem por regiões utilizando a informação espectral de cada "pixel", atrelado a informação espacial que envolve a relação com seus vizinhos, neste processo foi utilizado o classificador Máxima Verossimilhança (MaxVer). Este considera a ponderação das distâncias entre as médias dos valores dos pixels das classes, utilizando parâmetros estatísticos (Nascimento et. al, 2016).

As variáveis foram convertidas para o formato matricial e reclassificadas, aos respectivos componentes de legenda recebendo valores de custos em relação ao objetivo da presente análise, estes foram atribuídos a cada classe temática da variável (Louzada et al, 2010). As classes que inviabilizam a implementação dos corredores ecológicos receberam valores mais elevados, em uma escala de variação de 1 a 100. Para este estudo foram utilizadas as variáveis de Uso e Cobertura da Terra, Declividade, Área de Preservação Permanente - APP's.

As variáveis selecionadas possuem o objetivo de indicar a viabilidade de implementação dos corredores ecológicos. Após o processamento observaram-se locais que poderiam inviabilizar a criação dos corredores ecológicos, como as áreas urbanizadas, estes obtiveram custos mais elevados, enquanto classes com cobertura vegetal foram consideradas áreas viáveis para consolidação destes corredores, recebendo assim menores valores de custos. O mesmo ocorreu com a reclassificação dos dados de declividade, onde foi possível identificar áreas que possibilitam ocupações irregulares, bem como locais com usos restritos pela legislação que facilitem a implantação de corredores ecológicos. Dessa forma foram inferidos os custos de acordo com as classes e variáveis expostas nos Quadro 02 a 04, abaixo: 
USO E COBERTURA DA TERRA

Floresta

Vegetação Secundária

Área Urbana

Recursos Hídricos

\section{CUSTOS}

1

10

100

1

Quadro 02: Custos de Uso e Cobertura da Terra. (Lousada et al., 2010).

\section{DECLIVIDADE}

0 A 5

5 A 15

15 A 20

$>20$

Quadro 03: Custos de Declividade.

(Lousada et al., 2010).

\section{CUSTOS}

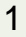

100

25

2
Área de Preservação Permanente

Áreas com Preservação Permanente

Áreas sem Preservação Permanente

Quadro 04: Custos de Área de preservação. (Lousada et al., 2010).

\section{CUSTOS}

1

50

As APP's foram consideradas áreas conformes à legislação vigente, ou seja, somente aquelas áreas que ainda estão preservadas e recobertas com a vegetação de floresta estacional semidecidual, campo rupestre e afloramento rochoso (nascentes, cursos d'água, corpos d'água e topo de morro). No caso da variável de Uso e Cobertura da Terra, consideram-se manchas urbanas que quanto maior a distância das áreas urbanas maior aptidão para corredor ecológico, bem como se levou em consideração as barreiras existentes no ambiente urbano como rodovias e grandes empreendimentos.

Após o processamento e hierarquização dos dados utilizou-se a extensão Corridor Designer Toolbox_v0.2, para cálculo da matriz com atribuição de pesos e notas proporcionais à criação de uma escala de intervalo, sendo utilizado em escala ordinal ou nominal, desde que os eventos sejam hierarquizados segundo a escala de valorização (Figura 02). 


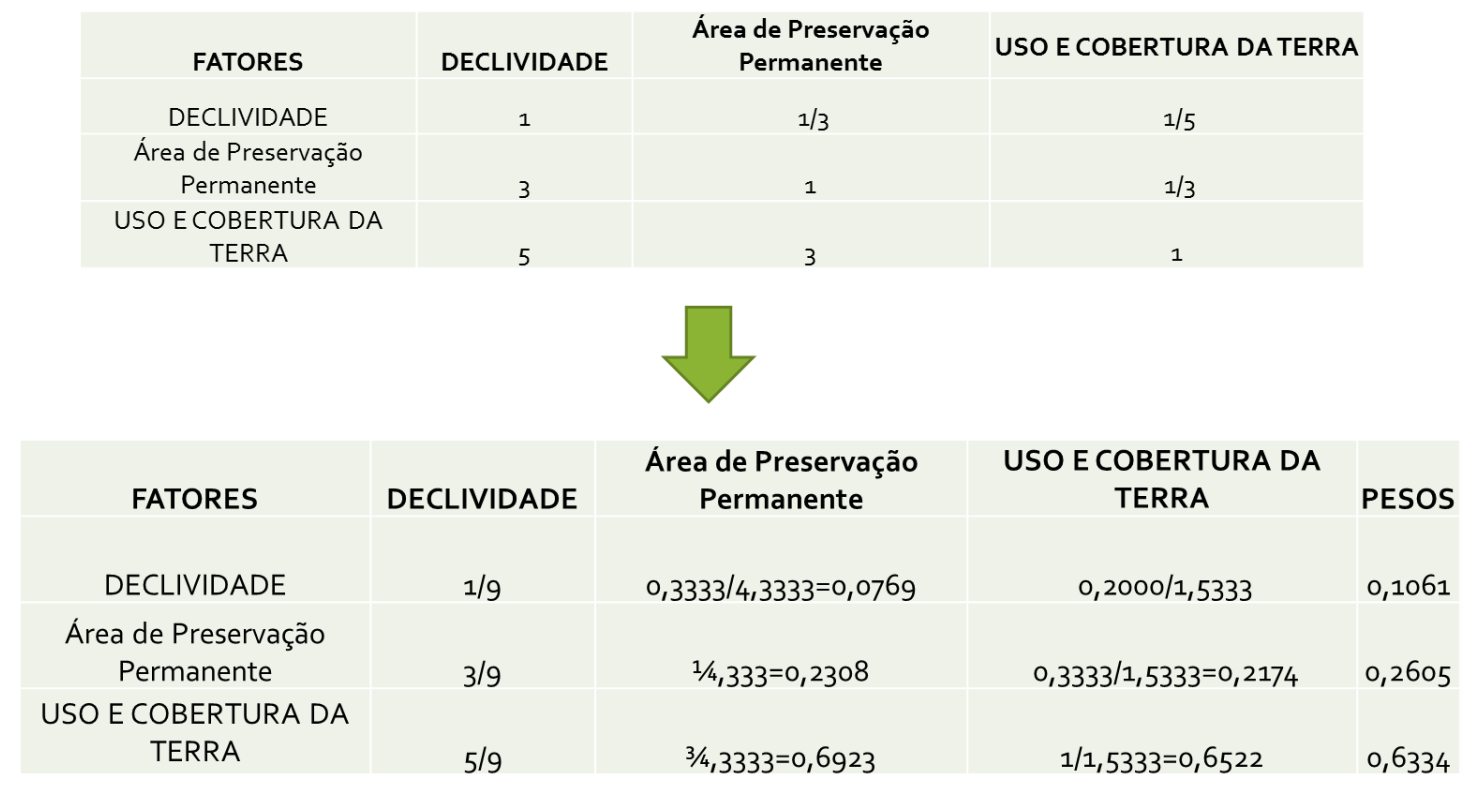

Figura 02: Cálculo da Matriz para os Corredores Ecológicos da Ilha do Maranhão

(Louzada et. al, 2010; Rocha; Masullo, 2016).

Como resutado final, alcançou-se um conjunto de dados em formato matricial que posteriormente foram reclassificados e convertidos em formato vetorial para formação do banco de dados temático utilizado na confecção dos layouts finais dos mapas, que serviram como base para as inferências geográficas realizadas.

\section{CORREDOR ECOLÓGICO COMO CORREDOR VERDE URBANO}

Segundo Ganen (2005), os corredores ecológicos estão previstos desde 1993, no Decreto no 750/93. Dea acordo com a resolução CONAMA os corredores ecológicos são remanescentes caracterizados por uma faixa de cobertura vegetal existente entre remanescentes de vegetação primária em estágio médio e avançado de regeneração, capaz de propiciar habitat ou servir de área de trânsito para a fauna residente nos remanescentes. (Brasil, 1996)

Complementando o conceito Ayres et. al (2005) coloca que o corredor ecológico está muito atrelado a outros conceitos e mecanismos de conservação ambiental, como por exemplo, Unidades de Conservação Ambiental e Áreas de Proteção Ambiental.

Neste estudo os corredores ecológicos são considerados como as grandes extensões de ecossistemas florestais biologicamente prioritários, delimitados em grande parte por conjuntos de unidades de conservação (existentes ou propostas) e pelas comunidades ecológicas que contém. O manejo integrado dos corredores ecológicos visa facilitar o fluxo de indivíduos e genes entre populações e subpopulações, aumentando a probabilidade de sua sobrevivência em longo prazo e assegurando a manutenção de processos ecológicos e evolutivos em larga escala.

O conceito de corredores ecológicos permite ainda o incremento do grau de conectividade entre as áreas naturais remanescentes, sob diferentes categorias de proteção e manejo, por meio de estratégias de recuperação de ambientes degradados, quando considerado compatível.

O programa piloto para a conservação das florestas tropicais do Brasil, elaborado em 2007 pelo Ministério do Meio Ambiente, também ressalta essas características:

Corredores Ecológicos são definidos, neste Projeto, como áreas que contêm ecossistemas florestais biologicamente prioritários e viáveis para a conservação da biodiversidade, compostos por conjuntos de unidades de conservação, terras indígenas e áreas de interstícios. Sua função é propiciar uma proteção efetiva da natureza, reduzindo ou prevenindo a fragmentação das florestas existentes por meio da interligação entre diferentes modalidades de áreas protegidas e outros espaços com diferentes usos do solo (Brasil, 2007: 11). 
Portanto, Áreas de Proteção Permanente são áreas com grande potencial para a implementação de corredores ecológicos. A diferença entre outras Unidades de Conservação, Área de Proteção Permanente e corredores ecológicos é que este último não é apenas um decreto ou uma lei, mas um projeto e um planejamento de manutenção da biodiversidade cuja área de abrangência é maior que a área de projeto ou intervenção, pois relaciona diferentes Unidades de Conservação.

Atualmente, o foco na implementação de corredores ecológicos tem se dado em áreas rurais, longe das cidades. Considerando as condições atuais das Unidades de Conservação nos municípios da RMGSL, este projeto responde, ainda que parcialmente, a questão: é possível pensar em corredores ecológicos em meios urbanos?

\subsection{Corredores Ecológicos em Meio Urbano}

Em meio urbano e regiões metropolitanas, as áreas protegidas tornam-se habitats fragmentados, o que representa a maior ameaça para a biodiversidade destas localidades (Tabarelli; Gascon, (2005). Entre as consequências desta realidade estão: o isolamento das formações e populações remanescentes; alterações nos fluxos gênicos; intensificação das competições intra e interespecíficas; alterações da estrutura e qualidade de habitats; extinções de espécies e perda de biodiversidade (Metzger, 1998, Primack; Rodrigues, 2001).

Uma das soluções apontadas por diversos autores para minimizar os efeitos da fragmentação é a criação de corredores ecológicos, como forma de promover a conectividade entre remanescentes, permitindo o fluxo gênico de indivíduos facilitando a dispersão de espécies e a recolonização de áreas degradadas, além de auxiliar na conservação dos recursos hídricos e do solo (Brasil 2006, Primack; Rodrigues 2001).

No Brasil, temos vários exemplos de corredores ecológicos em meio urbano, em especial na cidade de Manaus (Agência Brasil, 2017), uma metrópole localizada no meio da maior floresta tropical do mundo, na Amazônia. O objetivo destes corredores é interligar zonas fragmentadas de florestas, tornando possível a conectividade entre a fauna e a flora, e assim, preservando-a.

Ainda é possível observar no meio urbano a existência de grandes áreas verdes. Na RGMGSL, por exemplo, temos o Parque Estadual do Rangedor, Parque Estadual do Bacanga e as APA's do Itapiracó, Maracanã, Upaon-Açu - Miritiba - Alto Preguiças, Baixada Maranhense, Reentrâncias Maranhenses, além do Parque das Dunas, em processo de criação (Masullo, 2015). Estas áreas permaneceram preservadas devido a diversos fatores, como por exemplo, o crescimento urbano disperso e fragmentado de São Luís, praticado durante todo o século XX e até os dias atuais; planos urbanísticos que demarcavam áreas de proteção ambiental, como o Plano de Expansão da Cidade de 1956 e os planos diretores posteriores, além de leis ambientais, que com o passar dos anos, tornaram-se mais rigorosas e dificultaram a ocupação destas áreas, seja pelo setor imobiliário, seja por aglomerados subnormais (Lopes, 2006). Estas áreas verdes remanescentes, assim como os corredores ecológicos inseridos em meio rural, possuem um grande potencial para realizar suas funções e, em geral, possuem rios e córregos, que enfrentam graves ameaças devido à expansão da cidade.

A criação de corredores ecológicos nestas áreas serviria como um instrumento a mais para impedir que estas UC's se degradem ainda mais, e por consequência, deixem de existir. Entre os fatores que estão levando a grandes alterações na dinâmica da paisagem destas áreas, pode-se destacar o desmatamento, com a impermeabilização acelerada e excessiva do solo, que já afeta a maioria dos rios e córregos das áreas urbanas. Ademais, estas UC's se encontram nas bordas da cidade formal, próximas à infraestrutura e serviços, atraindo populações de baixa renda, que precisam dos benefícios da cidade formal e enfrentam os riscos da ilegalidade (Maricato, 2000), além dos riscos geofísicos de inundações, incêndios e desmoronamentos, muitas vezes causados pelo próprio processo de ocupação da Unidade de Conservação.

A partir destas constatações, a pesquisa apontou a necessidade de mesclar os conceitos de corredores ecológicos com o de corredor verde urbano. O corredor verde urbano é associado a espaços livres, lineares ou não, ao longo de elementos naturais, como frentes ribeirinhas, cursos de água, canais, etc. configurando parques, reservas naturais ou de património cultural, inclusive em áreas habitacionais. Estes corredores verdes urbanos possuem uma função ecológica importante para a biodiversidade do local, mas também possuem funções sociais relevantes, como espaços para recreio e lazer; vias de circulação de meios alternativos (bicicleta, caminhada, patins, etc.); valorização da paisagem; realização de eventos culturais e outras. 
No entanto, a criação destes corredores verdes urbanos carece de uma gama de medidas, como a arborização de ruas e avenidas atrelada à construção de ciclovias, quadras e outros espaços voltados ao lazer; implementação de um sistema de poda eficiente, para possibilitar a manutenção da paisagem natural; estímulos direcionados à manutenção de quintais arborizados nos bairros e regiões do entorno, com incentivos fiscais como a diminuição do IPTU; e o desenvolvimento de campanhas socioeducativas que é uma medida necessária em todos os âmbitos deste estudo, a fim de engajar a população nesse processo.

A proposta de corredor ecológico em meio urbano, portanto, deve colocar em evidência as funções que aquela área/intervenção possui, trazendo uma conscientização coletiva e um significado real daquela área (que em geral encontra-se abandonada, quase sem nenhum cuidado) para toda a cidade. No entanto, esta intervenção deve considerar diversos aspectos e partir de critérios bem definidos.

O planejamento de corredores ecológicos, principalmente em áreas urbanas, exige a análise e integração de vários fatores, a partir de um conjunto de dados georreferenciados, correlacionando os aspectos e condicionantes socioeconômicos e ambientais e otimizando a preservação destas áreas (Martins et al, 1998). O primeiro passo é a indicação da possível configuração do corredor ecológico entre as Unidades de Conservação estudadas, assim como das diretrizes de projeto a serem adotadas.

\section{IMPLANTAÇÃO DE CORREDORES ECOLÓGICOS NA GRANDE SÃo LUÍS}

Atualmente, São Luís e os municípios de Paço do Lumiar, Raposa e São José de Ribamar que estão localizados na llha do Maranhão, que junto aos municípios de Alcântara, Axixá, Bacabeira, Cachoeira Grande, Icatu, Morros, Presidente Juscelino, Rosário e Santa Rita conformam a Região Metropolitana da Grande São Luís (Figura 03), e sofrem com os impactos da forte interação e concentração econômica, social e urbana, sem contar com um sistema consistente de planejamento e gestão metropolitana compartilhada, que minimize os riscos desta interação e apresente soluções para os problemas vividos pela população.



Figura 03: Mapa de Localização da Região Metropolitana da Grande São Luís.

Fonte: Masullo; Lopes, 2016. 
O presente estudo demonstra a importância de proteger áreas com relevante interesse social, econômico e ambiental, mas principalmente mostra a necessidade de se efetivar a preservação dessas unidades da paisagem, visando a manutenção da qualidade de vida para as gerações presentes e futuras.

Essa necessidade torna-se um desafio ainda maior quando se observa a formação das nossas grandes cidades, hoje reconhecidas como metrópoles, onde se percebe que seja qual for sua configuração territorial, estas tendem à fragmentação e à dominação por interesses políticos locais, que não abrem mão do poder em favor do bem coletivo (Masullo; Lopes, 2016).

Para tanto, faz-se necessária a criação de novas estratégias que objetivem a implementação de políticas públicas integradas com a realidade e principalmente, alinhadas ao contexto local e as funções públicas de interesse comum listadas pela Lei $n^{\circ} 174 / 2015$. Sob essa perspectiva, o estudo se desenvolve a partir de técnicas e procedimentos metodológicos baseado em Gascon; Tabarelli (2005), Louzada et al. (2010), Araújo et al. (2014), para o desenvolvimento de propostas viáveis de corredores ecológicos para os municípios da llha do Maranhão.

\subsection{Corredor APA do Itapiracó / APA Upaon-Açu}

Dentre os corredores ecológicos identificados como viáveis está o corredor que interliga as Unidades de Conservação da APA do Itapiracó e APA Upaon-Açu - Miritiba - Alto do Rio Preguiças, passando pelos municípios de Paço do Lumiar, São José de Ribamar e a capital maranhense, São Luís (Figura 04).

O corredor supracitado conecta as UC's em um percurso de 4,5km de extensão, através da bacia hidrográfica do Rio Paciência, integrado por seus afluentes, passando pelo Rio Itapiracó e conectando-se ao rio Boa Vista até chegar ao curso principal do Rio Paciência.



Figura 04: Proposta do Corredor APA do Itapiracó/APA Upaon-Açu-Miritiba-Alto do Rio Preguiças. Elaboração própria a partir dos dados da pesquisa. 
A partir do percurso apresentado, percebe-se que há grande viabilidade na implementação do corredor em questão, tendo em vista a dinâmica da paisagem existente no local, com declividade baixa variando entre 0 e 10\% e com a existência de mata ciliar protegendo o curso dos rios Boa Vista e Itapiracó, o que possibilita, a partir de determinadas intervenções urbanísticas, a consolidação do corredor ecológico na localidade.

No entanto, é visível a necessidade de intervenções urbanísticas na região, tanto para a efetivação das UC's quanto do corredor, tendo em vista a dinâmica territorial instituída na localidade, estruturada pelo avanço da especulação imobiliária e pela ineficácia do planejamento e monitoramento dos Governos Federais e Municipais.

Esse cenário propiciou a formação de uma área extremamente adensada, circundada por bairros como Cohab, Cohatrac, Parque Vitória e Turú, bem como diversos empreendimentos do Programa Minha Casa Minha Vida, e grandes empreendimentos privados.

Segundo Masullo (2013), a ocupação da região resultou tanto na fragmentação, quanto na dispersão espacial dos processos produtivos em diferentes escalas e como resultado influenciou a reorganização do espaço, redistribuindo e reestruturando os processos produtivos, o que impulsionou ainda mais a ocupação da região, com avanço de aproximadamente $40 \%$ nos últimos 20 anos (Figura 05).

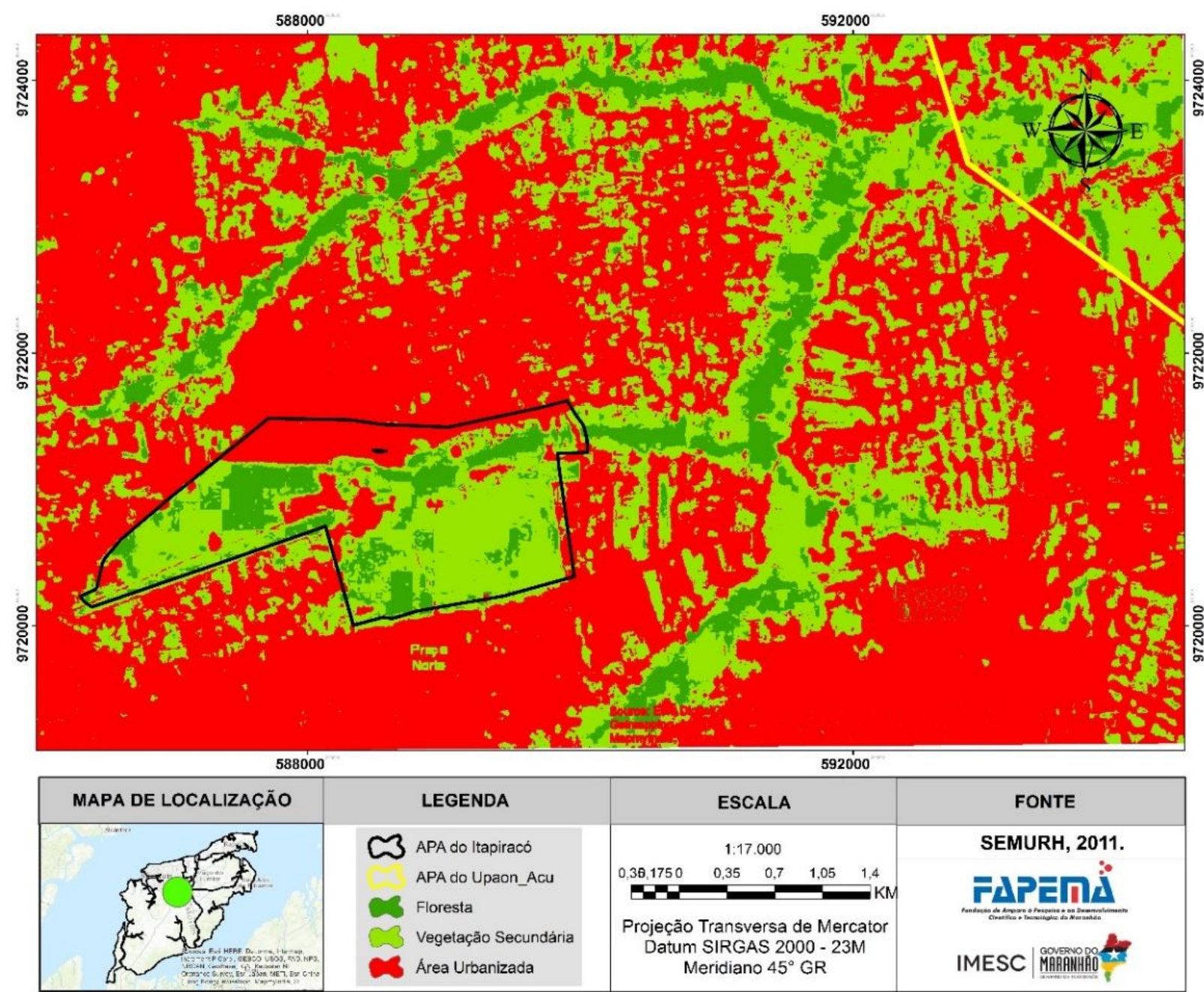

Figura 05: Uso da Terra do entorno da APA do Itapiracó / APA Upaon-Açu - Miritiba - Alto do Rio Preguiças.

Elaboração própria a partir dos dados da pesquisa.

O processo intenso de urbanização da região nos últimos anos propiciou grande demanda por serviços públicos de segurança, educação, saúde e saneamento básico como esgotamento sanitário, abastecimento de água e coleta de resíduos. Segundo o IBGE (2010), a área possui percentuais inferiores a $25 \%$ de coleta de efluentes e $50 \%$ de coleta de lixo, acarretando no lançamento de efluentes in natura nos cursos d'água, na derrubada de mata ciliar e assoreamento do leito dos rios.

\subsection{Diretrizes de Projeto para o Parque Urbano do Itapiracó/Upaon-Açu}


A realidade identificada no entorno do Corredor Ecológico da APA do Itapiracó / APA Upaon-Açu interfere diretamente na qualidade de vida da população e na sustentabilidade ambiental das áreas protegidas da região. Assim, para que se elabore o projeto e implemente este Corredor Ecológico da APA do Itapiracó / APA Upaon-Açu mesclando-o com o modelo conceitual de corredor verde urbano, faz-se necessário as seguintes intervenções urbanísticas específicas para a região:

1. Revitalização dos Rios Itapiracó, Boa Vista e Paciência;

2. Manutenção e recuperação de áreas de preservação permanente;

3. Recuperação e recomposição florística de áreas degradadas;

4. Ampliação da coleta e tratamento de efluentes;

5. Relocação dos habitantes que residem em áreas de risco a inundações.

Corredores ecológicos são zonas onde devem ser adotadas estratégias de preservação da biodiversidade local, protegendo de fatores externos, como a urbanização acelerada, a zona do corredor. A abordagem adotada no projeto, portanto, deve conciliar as funções do corredor ecológico com as características de um parque urbano linear, capaz de organizar o contato e a convivência dos usuários e moradores da área urbana com esta zona preservada. E maior será o sucesso desta intervenção, quanto mais ela conseguir envolver os próprios moradores e usuários nas atividades de preservação da área.

Segundo Karman (2013), o corredor ecológico possui finalidades e objetivos específicos. Pode servir como habitat, ao garantir as condições necessárias para a reprodução de diversas espécies de animais e vegetais, com a probabilidade de sucesso neste quesito aumentada proporcionalmente à largura do corredor ecológico.

Outro objetivo dos corredores ecológicos a ser considerado nos projetos de implantação deste parque urbano é a da dispersão, ou seja, criar condições necessárias para que as espécies possam transitar pelo corredor, buscando alimentos e parceiros para fins de reprodução. Portanto, o contato entre usuários do parque e as espécies deve ocorrer apenas de forma eventual, resguardando o livre trânsito e aumentando a possibilidade de interação entre espécies da fauna e flora.

Outra função dos corredores ecológicos é a de barreira e de filtro que, com a vegetação, impede que impurezas e poluentes provenientes do escoamento superficial atinjam a biodiversidade aquática, por exemplo (Karman, 2013). Esta barreira pode e deve ser reforçada pelas estratégias de projeto, como a adoção de cercas vivas, da pavimentação adequada e o uso equilibrado da iluminação.

Por último, estes corredores podem exercer a função de fonte e sumidouro, que seria corredores projetados para a manutenção da vida aquática, mas limitados ou incapazes quanto à manutenção da biodiversidade terrestre de animais silvestres.

Na terceira e última etapa da pesquisa, em desenvolvimento, a equipe deve respeitar e estabelecer como diretrizes para a definição do projeto de espaço público e consequente configuração do futuro Parque Urbano do Itapiracó/Upaon-Açu as seguintes premissas:

a. Caracterizar a área de projeto e avaliar seu potencial dentro do contexto ecológico e urbano;

b. Definir o traçado final e o perímetro do parque, considerando a necessidade de remoção do menor número de edificações possível ao longo do trajeto do rio.

c. Buscar a integração das Unidades de Conservação nos diferentes ambientes do parque urbano, favorecendo o fluxo gênico entre as mesmas.

d. Delimitar, limpar, recuperar (inclusive com replantio) e monitorar as áreas verdes urbanas degradadas na área de projeto;

e. Sensibilizar e incentivar a comunidade a participar do processo de recuperação e proteção do parque urbano, contribuindo para a formação de uma consciência ecológica entre os moradores;

f. Fomentar os usos adequados para a preservação da área;

g. Buscar sempre a maior largura possível para o parque urbano, em todo o seu comprimento;

h. Garantir o livre trânsito das espécies (o fluxo gênico), com o menor número de edificações possível;

i. Proteger a área com estratégias de projeto como vedações, pavimentação, iluminação e mobiliário;

j. Sugerir formas de explorar o potencial das áreas do projeto, de forma isolada ou em conjunto, para a melhoria do ecossistema e da qualidade de vida da população;

k. Sinalizar dos pontos de passagem de animais silvestres para alertar motoristas e moradores;

I. Garantir a acessibilidade em todos os setores da área de projeto; 
m. Implantar sistema de comunicação visual que reforce a identidade do parque urbano e suas funções.

Além destas diretrizes gerais para o projeto do parque urbano, também se faz necessário considerar as estratégias de proteção dos recursos hídricos da área:

a. Isolar e proteger os rios Boa Vista e Itapiracó, evitando o despejo de resíduos e o assoreamento da calha;

b. Definir a largura máxima de uma faixa de preservação ao longo dos rios de acordo com as diversas situações fáticas e com os recursos disponíveis para o projeto;

c. Avaliar a possibilidade de remoção de edificações e isolamento de áreas, focando nos pontos de descontinuidade para formação do corredor ecológico.

Essas diretrizes de projeto conduzirão a resultados práticos que devem incluir a elaboração e desenvolvimento de campanhas de educação socioambiental, a fim de engajar a população nesse processo; a criação de espaços para recreio e lazer; a implantação de vias de circulação de meios alternativos (bicicleta, caminhada, skate e patins, e outros.); espaços para realização de eventos culturais de pequeno porte em horários definidos, por exemplo.

O projeto também deve prever instrumentos de gestão eficientes, voltados para a área, como a adoção de um sistema de poda eficiente, para possibilitar a manutenção e valorização da paisagem natural, mas também para o entorno da área, com ações como a arborização de ruas e avenidas e a possível extensão de ciclovias, e estímulos direcionados à manutenção de quintais arborizados nos bairros e regiões do entorno - com incentivos fiscais como a diminuição do IPTU, por exemplo.

\section{CONCLUSÕES}

Com o objetivo de desenvolver propostas para criação de corredores ecológicos que interliguem as Unidades de Conservação da Grande São Luís, na Ilha do Maranhão, o estudo correlacionou aspectos e condicionantes socioeconômicas e ambientais, indicando a importância do uso equilibrado das áreas protegidas como fator primordial para a preservação destas áreas em meio urbano. Ademais, o estudo constatou que no contexto da llha do Maranhão, em meio ao seu consolidado processo de urbanização, há obstáculos e interferências em alguns trajetos que impedem a proposição de corredores ecológicos da forma como estão caracterizados na legislação.

A partir destas constatações, a pesquisa apontou a necessidade de mesclar os conceitos de corredores ecológicos com o de corredor verde urbano. O corredor verde urbano é associado a espaços livres, neste caso necessariamente lineares, ao longo de elementos naturais, como frentes ribeirinhas, cursos de água, canais, etc. configurando parques, reservas naturais ou de património cultural, inclusive em áreas habitacionais.

A pesquisa indicou, portanto, a necessidade de implantação do corredor ecológico entre a APA do Itapiracó e a APA Upaon-Açu/Miritiba/Alto Preguiças, nos moldes de um parque urbano linear, ao longo dos rios Boa Vista e Itapiracó, como forma de integrar as duas Unidades de Conservação, favorecendo o fluxo gênico e o controle da poluição do solo e água. Do ponto de vista urbano, a recuperação das margens dos rios evitará a disseminação de doenças infectocontagiosas, contribuindo para a qualidade hídrica e promovendo melhoria na qualidade de vida da população.

No entanto, o estudo indica que o projeto do Parque Urbano do Itapiracó/Upaon-Açu deve adotar estratégias e soluções que Ihes confiram as características necessárias - largura, mais áreas protegidas que áreas compartilhadas, sinalização, áreas de recuperação ambiental, poucas edificações, etc. - capazes de resguardar as finalidades e objetivos específicos de um corredor ecológico.

Portanto, a etapa atual de desenvolvimento do trabalho propõe a definição e detalhamento de uma intervenção para implantação do Parque Urbano do Itapiracó/Upaon-Açu, a partir de uma análise da paisagem que considerou suas singularidades e complexidades e do entendimento dos fatores que produzem e reproduzem o espaço e determinam suas características social, econômicas e ambientais. Assim, o estudo fornecerá bases para que se otimize e se implemente políticas públicas e projetos urbanos intrinsecamente ligadas à conservação da geodiversidade e da qualidade de vida em escala metropolitana. 


\section{BIBLIOGRAFIA}

ANDERSON, A. B; JENKINS, C. N. Applying nature's design: corridors as a strategy for biodiversity conservation. New York: Columbia University Press, 2006.

ARGYRIOU, A.V. et al. GIS multicriteria decision analysis for evaluation and mapping of landscape deformation neotectonics: A case study from Crete. In: Geomorphology, 262 -274. 2016.

ARAUJO, Ricardo Murilo Padilha de. et. al. Planejando corredores ecológicos para restauração florestal em paisagens fragmentadas: Complexo Industrial de SUAPE.In: V Congresso Brasileiro de Gestão Ambiental. Belo Horizonte - MG.2014.

AYRES, José Márcio, et al. Os corredores ecológicos das florestas tropicais do Brasil. ; fotografias Luiz Claudio Marigo. Belém, PA : Sociedade Civil Mamirauá, 2005.

BUSQUETS, Joan. Presente y Perspectivas del Urbanismo. In: Sociedade e Território. n. 37/38. Porto - PT: Edições Afrontamento, 2004. p. 46 - 60.

BRASIL. Conselho Nacional do Meio Ambiente - CONAMA. Resolução no 06, de 24 de outubro de 1996. Estabelece corredor de vegetação área de trânsito a fauna. Brasília: CONAMA, 1996.

BRASIL. Instituto do Meio Ambiente e dos Recursos Naturais Renováveis. Corredores Ecológicos experiências em planejamento e implementação / Ministério do Meio Ambiente, Secretaria de Biodiversidade e Florestas. - Brasília: MMA, 2007.

BRASIL. Lei no 9.985, de 18 de julho de 2000. Regulamenta o art. 225, § 10, incisos I, II, III e VII da Constituição Federal, institui o Sistema Nacional de Unidades de Conservação da Natureza e dá outras providências. Diário Oficial [da] União, Brasília, DF, 19 de julho de 2000.p.1-23.

BRASIL. Ministério do Meio Ambiente - MMA. Série corredores ecológicos- 12 anos de trabalho pela conservação da biodiversidade nacional. Brasília, 2015.

COSTA, N. F. A. da et al. Efeitos da urbanização na área de Proteção Ambiental do Itapiracó, São Luís, MA. Boletim do Laboratório de Hidrobiologia, 2008.

COUTINHO, Luciano Melo. Zoneamento de áreas potenciais para reflorestamento via lógica Fuzzy e AHP. IN: XVII SBSR. INPE. João Pessoa. 2015.

DIAS, Valdirene Silva Brito. AHP na modelagem da vulnerabilidade ambiental do mini corredor ecológico serra das onças (BA). In: Revista Brasileira de Cartografia 1363-1377. 2014.

GAUER. Natália Peppes. Avaliação da vulnerabilidade ambiental por meio de um modelo de análise multicritério no norte da planície costeira do Rio Grande do Sul, Brasil. Monografia em Ciências Biológicas. Universidade Federal do Rio Grande do Sul. IMBÈ, 2015.

FERREIRA, Suzana Barros. O Programa Polis e a Componente Ambiental - Três abordagens de integração e acompanhamento. Lisboa: Parque EXPO 98, 2008.

GANEM, Roseli Senna. Corredores Ecológicos. Consultoria Legislativa, Câmara dos Deputados. 2005.

GOVERNA, F., SACCOMANI, S. From urban renewal to local development. New conceptions and gobernance practices in the Italian peripheries. In: Planning Theory and Practice. vol. 5. n. 03. 2004. p. $327-348$.

KARMAN, Vânia. Proposta de interligação das glebas do Parque Estadual de Vassununga (Santa Rita do Passa Quatro, SP). Piracicaba, 2003.

LOPES, José Antonio Viana. São Luís no século XXI. In: ESPÍRITO SANTO, José Marcelo (Org.). São Luís: uma leitura da cidade (88-92). São Luís: Instituto de Pesquisa e Planificação da Cidade - IPPC, 2006.

LOUZADA, F. L. R de O. et al. Delimitação de corredores ecológicos no ArcGIS 9.3. Mundo da Geomática. Universidade Federal do Espirito Santo, 2010. 
MARQUES, Luciene et al. Metodologia para a definição de áreas favoráveis para implantação de corredor ecológico, utilizando ferramenta do Sistema de Informação Geográfica. Anais XV Simpósio Brasileiro de Sensoriamento Remoto - SBSR, INPE p.4436. Curitiba, PR. 2011.

MARANHÃO. Secretaria de Estado das Cidades e desenvolvimento Urbano. A Grande São Luís: Estudo Técnico. São Luís: SECID, 2017.

MARICATO, Ermínia. VAINER, Carlos. ARANTES, Otília. A cidade do pensamento único: desmanchando consensos. Petrópolis, RJ: Vozes, 2000.

MASULLO, Yata Anderson Gonzaga. Avaliação da dinâmica espacial da dengue em relação às questões socioambientais no distrito sanitário da COHAB no município de São Luís - MA. Dissertação (Mestrado) - Universidade Estadual do Maranhão, Programa de Pós-Graduação em Desenvolvimento Socioespacial e Regional, 2013.

MASULLO, Yata Anderson Gonzaga. LOPES; José Antonio Viana Os desafios da gestão interfederativa frente aos indicadores sociais da Região Metropolitana da Grande São Luís - MA. Rev. Tamoios, São Gonçalo (RJ), ano 12, n. 1, págs. 62-83, jan/jun. 2016.

MASULLO, Yata Anderson Gonzaga. Corredores Ecológicos na Região Metropolitana da Grande São Luís. Relatório Final de Pesquisa. São Luís: FAPEMA. 2015.

MOORE, B., SPIRES, R. Chapte 10 - Monitoring and Evaluation. In: Urban Regenerate: a handbook. London: SAGE, 2000.

MORIN, E. et al. Educar na era planetária: o pensamento complexo como método de aprendizagem pelo erro e incerteza humana. Trad. Sandra Trabucco Valenzuela. São Paulo: Cortez; Brasília; UNESCO, 2003.

PEDLOWSKI, M. et al. A criação de áreas protegidas e os limites da conservação ambiental em Rondônia.

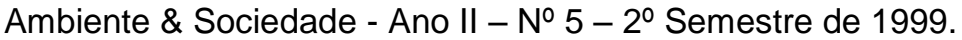

PENTEADO, H.M; ALVAREZ, C.E. de. Corredores verdes urbanos: estudo da viabilidade de conexão das áreas verdes de Vitória. Paisagem Ambiente: ensaios - n. 24 - São Paulo. 2007.

PRIMACK, R.B.; RODRIGUES, E. Biologia da conservação. Londrina. 2001.

PEREIRA, V.H.C; CESTARO, L.A. Corredores ecológicos no Brasil: avaliação sobre os principais critérios utilizados para definição de áreas potenciais. Caminhos de Geografia Uberlândia v. 17, n. 58 p. 16-33. 2016.

RAFFO; Jorge Gustavo da Graça. O processo analítico hierárquico e seu uso na modelagem do espaço geográfico. In: Revista do Departamento de Geografia - USP, Volume Especial 30 Anos. p. 26-37. São Paulo. 2012.

ROCHA, Roberta Capim; MASULLO, Y. A. G. Corredores Ecológicos na llha do Maranhão. Relatório de Pesquisa. Fundação de Amparo à Pesquisa e ao Desenvolvimento Científico e Tecnológico do Maranhão - FAPEMA. São Luís. 2016.

SHAO, Huaiyong. A method to the impact assessment of the returning grazing land to grassland project on regional eco-environmental vulnerability. In: Environmental Impact Assessment Review, 155-167. 2016.

SAHOO. S. etal. Environmental vulnerability assessment using Grey Analytic Hierarchy Process based model. In: Environmental Impact Assessment Review. 145-154. 2016.

SAITO, Nathalia Suemi et. al. Geotecnologia e Ecologia da Paisagem no Monitoramento da Fragmentação Florestal. In: Revista Floresta e Ambiente. 2015.

SEOANE, C. E. S. et al. Corredores ecológicos como ferramenta para a desfragmentação de florestas tropicais. Pesquisa Florestal Brasileira, Colombo, v.30, n.63, p. 207-216, ago./out. 2010. 
SILVA JUNIOR, Celso Henrique Leite. Lógica Fuzzy e Processo Analítico Hierárquico - AHP na avaliação da qualidade ambiental de nascentes. In: Revista Eletrônica em Gestão, Educação e Tecnologia Ambiental Santa Maria, v. 19, n. 2, mai-ago., p. 292-303. Santa Maria - RS. 2015.

TABARELLI, M; GASCON, C. Lessons from fragmentation research: improving management and policy guidelines for biodiversity conservation. Conservation Biology, vol. 19, no. 3, p. 734-739. 2005.

VALENTI, M. W. et al. Educação ambiental em unidades de conservação: políticas públicas e a prática educativa. Educação em Revista | v.28 | n.01 | p.267-288 | Belo Horizonte. 2012.

Fontes eletrônicas:

Agência Brasil. Manaus quer aumentar número de corredores ecológicos urbanos. 2008. Disponível em: $<$ http://memoria.ebc.com.br/agenciabrasil/noticia/2008-12-14/manaus-quer-aumentar-numero-decorredores-ecologicos-urbanos> (Consulta: 02/02/2017). 